\title{
Prevalence and molecular characterization of group B streptococcus in pregnant women from hospitals in Ohangwena and Oshikoto regions of Namibia
}

\author{
Erastus Lafimana Haimbodi, Munyaradzi Mukesi and Sylvester Rodgers Moyo*
}

\begin{abstract}
Background: The main purpose of this study was to investigate the prevalence rate, antimicrobial susceptibility patterns and molecular characteristics of Streptococcus agalactiae isolated from pregnant women at 35 weeks of gestation and above, who attended antenatal screening at selected hospitals in Ohangwena and Oshikoto regions of Namibia.

Results: Out of 210 women screened for Group B Streptococcus (GBS), 12 (5.7\%) were colonised of which 25.0\% were colonised rectovaginally, $58.0 \%$ vaginally and $17.0 \%$ rectally. No significant association was reported between GBS colonisation and maternal age, geographic location, marital status, education, employment, parity, still births and miscarriages ( $P$ values $>0.05$ ). Antimicrobial susceptibility was reported at $100 \%$ for ampicillin, penicillin \& ceftriaxone which are commonly used for empiric treatment of infection with GBS. Resistance to tetracycline was reported at 100\%. Tetracycline resistance gene tet(M) was present in $88.9 \%$ of the isolates only and none of the isolates presented with tet(O). Polysaccharide capsular type la was found in 9(50\%) and $\mathrm{lb}$ was found in 1(5.5\%) of the total isolates. The remaining isolates were not typeable using PCR.

Conclusion: Streptococcus agalactiae's positive rate was 5.7\% among the pregnant women examined. Sociodemographic and obstetric factors had no influence on GBS colonisation ( $P$ values $>0.05$ ). No resistance was reported to ampicillin, penicillin and ceftriaxone. No sensitivity was reported to tetracycline. Fifty percent of the isolates were capsular type la, 5.5\% were type Ib and $44.4 \%$ were not typeable using PCR. The study provides crucial information for informing policy in screening of GBS in pregnant women.
\end{abstract}

Keywords: Group B streptococcus, Molecular characterization, Antimicrobial susceptibility

\section{Background}

Streptococcus agalactiae ( $S$. agalactiae) is a grampositive bacterium which belongs to the Lancefield Group B streptococcus (GBS). It is part of the normal flora of the gastrointestinal and female genitourinary tracts, and it is present in the genital tract of about 20-

\footnotetext{
* Correspondence: srmoyo@nust.na

Department of Health Sciences, Faculty of Health and Applied Sciences, Namibia University of Science and Technology, Windhoek, Namibia
}

$60 \%$ of pregnant women [1]. Nearly $20-40 \%$ of healthy women are colonised by GBS, and $50-70 \%$ of infants born to these mothers become infected with it [2].

Group B streptococcus is a leading cause of neonatal sepsis and meningitis worldwide [3]. It is widely implicated in maternal infections such as endometritis and chorioamnionitis as well as neonatal infections such as pneumonia, meningitis, sepsis and septicaemia [4]. Mortality of GBS in neonates is over $50 \%$ and is particularly

C C The Author(s). 2021 Open Access This article is licensed under a Creative Commons Attribution 4.0 International License, which permits use, sharing, adaptation, distribution and reproduction in any medium or format, as long as you give appropriate credit to the original author(s) and the source, provide a link to the Creative Commons licence, and indicate if changes were made. The images or other third party material in this article are included in the article's Creative Commons licence, unless indicated otherwise in a credit line to the material. If material is not included in the article's Creative Commons licence and your intended use is not permitted by statutory regulation or exceeds the permitted use, you will need to obtain permission directly from the copyright holder. To view a copy of this licence, visit http://creativecommons.org/licenses/by/4.0/ The Creative Commons Public Domain Dedication waiver (http://creativecommons.org/publicdomain/zero/1.0/) applies to the data made available in this article, unless otherwise stated in a credit line to the data. 
high in preterm infants [3]. Vaginal colonisation by GBS during pregnancy is associated with premature delivery and still births [1].

The median prevalence of GBS in pregnant women in Africa was reported at $16 \%$ in 2009 [5]. The prevalence in Windhoek, Namibia was reported at 13.6\% in 2016 [6]. Furthermore, the colonisation rate in other Southern African countries was reported at $31.6 \%$ in Zimbabwe in 2000 [7], 37\% in South Africa in 2018 [8, 9], 21.2\% in Malawi in 2010 [10] and 1.8\% in Mozambique in 2008 [11].

Most studies done in Africa have shown a uniformity in sensitivity of GBS to penicillin and ampicillin which are the recommended drugs for prophylaxis against GBS. The Centres for Diseases Control and Prevention (CDC) recommends GBS screening in women at 35-37 weeks of gestation. Prophylaxis is given to pregnant women who are colonised by GBS, deliver infants with invasive GBS disease or are of unknown GBS status at delivery to prevent neonatal infection [12]. However, erythromycin \& clindamycin are recommended for patients who are allergic to penicillin [12]. Gene based resistance in GBS is encoded by ermB, ermA, ermTR, mefA, mefE, aphA-3, aad-6, tet $(\mathrm{M})$, tet $(\mathrm{O})$, int-Tn and mreA [13]. Despite the availability of the CDC guidelines, Namibia has not adopted an approach to screen for GBS in pregnant women.

Group B streptococcus is classified into ten common capsular types based on capsular polysaccharide antigens on the surface of the organism. These capsular types are Ia, Ib, II, III, IV, V, VI, VII, VIII and IX $[14,15]$. The most prominent capsular types in Southern Africa are type Ia, Ib, II, III and V [7, 8, 16-19]. The capsule is the main virulence factor for GBS. The study aimed to determine the prevalence and molecular characteristics of group B streptococcus isolated from pregnant women from selected rural settings of Namibia.

\section{Results}

\section{Prevalence of group B streptococcus}

A total of 12 out of the 210 participants, (5.7\%) tested positive for GBS colonisation, of which 7 (3.3\%) tested positive with vaginal swabs and $2(1.0 \%)$ tested positive with rectal swabs. A total of $3(1.4 \%)$ out of 210 participants tested positive with both rectal and vaginal swabs.

This study assessed the influence of different sociodemographic characteristics, age and obstetric factors on the rate of GBS colonisation in pregnant women screened.

The age of pregnant women screened in this study ranged from 16 to 49 years with mean age of 29 years and standard deviation of \pm 7 . Out of the total 210 pregnant women, 174 were living in rural, 9 in semi-urban and 27 in urban areas. One hundred and sixty (160) women were not married, while 50 were married. Those with qualifications below matric were 156, those with matric qualifications were 51 and those with tertiary qualifications were only 3 . Unemployed women were 168 and employed women were 42.

Out of the twelve colonised women, $75.0 \%$ was women aged between 20 and 39 years and $25.0 \%$ was women aged 40 years and above ( $P$ value 0.209 ). Majority of colonised women were rural based women $(83.3 \%)$ than urban living women (16.7\%) ( $P$ value 0.708$)$. Unmarried women colonised by GBS were 75.0 and $25.0 \%$ of colonised women were married ( $P$ value 0.921 ).

Majority of colonised women were those with educational level below matric (58.3\%) than those with matric qualifications $(41.7 \%)$ ( $P$ value 0.333$)$. The same scenario was found in terms of employment status, whereby $66.7 \%$ of unemployed women were colonised and only $33.3 \%$ of colonised women were employed ( $P$ value 0.234 ).

Majority of GBS colonised were unmarried, unemployed and rural based women aged between 20 and 39 years who never matriculated. Table 1 illustrates the rates of GBS colonisation based on various sociodemographic factors.

Among all GBS colonised women, women with three or more successful pregnancies were $50.0 \%$, while those with either one or two were $33.0 \%$ and those without any previous pregnancy were $16.7 \%$ ( $P$ value 0.659 ). Carriage of GBS was only shown in women without previous history of still births ( $P$ value 0.613 ). GBS colonised women without any history of miscarriages were $83.3 \%$ while those with a history of either 1 or 2 miscarriages were $16.7 \%$ ( $P$ value 0.471 ). Table 2 illustrates the association between obstetric factors and GBS colonisation.

The culture of rectal and lower vaginal swabs by both direct BCNA agar and Todd-Hewitt-BCNA agar yielded a total of 18 CAMP positive GBS isolates recovered from 12 women. These isolates were confirmed as $S$. agalactiae using real time $\mathrm{PCR}$, in which the target gene $s c p \mathrm{~B}$ for $\mathrm{C} 5$ a peptidase gene was amplified. Following gel electrophoresis, DNA amplicons approximately 255 base pairs on the gel were identified as $S$. agalactiae. No sequencing was performed in this study.

\section{Antimicrobial susceptibility patterns}

All 18 GBS isolates obtained from this study were tested individually for antimicrobial susceptibility to each of the antibiotics used, and all showed 100\% susceptibility to penicillin, ampicillin, ceftriaxone, clindamycin, erythromycin, vancomycin, linezolid and chloramphenicol. All isolates revealed $100 \%$ resistance to tetracycline. Intermediary sensitivity and inducible clindamycin resistance were reported for any organism. The frequencies of antimicrobial susceptibility patterns are illustrated in Table 3. 
Table 1 Association between socio-demographic factors and GBS colonisation

\begin{tabular}{|c|c|c|c|c|}
\hline Characteristic & Category & GBS non-colonised frequency $(n=198)$ & GBS colonised frequency $(n=12)$ & $P$ value \\
\hline \multirow[t]{3}{*}{ Age in years } & Below 20 & $12(6.1 \%)$ & $0(0.0 \%)$ & 0.209 \\
\hline & 20-39 & $166(83.8 \%)$ & $9(75.0 \%)$ & \\
\hline & 40 and above & $20(10.1 \%)$ & $3(25.0 \%)$ & \\
\hline \multirow[t]{3}{*}{ Geographic location } & Rural & $164(82.8 \%)$ & $10(83.3 \%)$ & 0.708 \\
\hline & Semi-urban & $9(4.5 \%)$ & $0(0.0 \%)$ & \\
\hline & Urban & $25(12.6 \%)$ & $2(16.7 \%)$ & \\
\hline \multirow[t]{2}{*}{ Marital status } & Not married & $151(76.3 \%)$ & $9(75.0 \%)$ & 0.921 \\
\hline & Married & 47 (23.7\%) & $3(25.0 \%)$ & \\
\hline \multirow[t]{3}{*}{ Educational level } & Below matric & $149(75.3 \%)$ & $7(58.3 \%)$ & 0.333 \\
\hline & Matric & $46(23.2 \%)$ & $5(41.7 \%)$ & \\
\hline & Tertiary & $3(1.5 \%)$ & $0(0.0 \%)$ & \\
\hline \multirow[t]{2}{*}{ Employment status } & Unemployed & $160(80.8 \%)$ & $8(66.7 \%)$ & 0.234 \\
\hline & Employed & $38(19.2 \%)$ & $4(33.3 \%)$ & \\
\hline
\end{tabular}

Ceftriaxone was performed using Kirby-Bauer disc diffusion method for all isolates.

Consistent minimum inhibitory concentrations (MICs) were observed in most antibiotics. These include ampicillin $(\leq 0.25 \mu \mathrm{g} / \mathrm{L})$, penicillin $(\leq 0.12 \mu \mathrm{g} / \mathrm{L})$, clindamycin $(\leq 0.25 \mu \mathrm{g} / \mathrm{L})$, chloramphenicol $(\leq 10 \mu \mathrm{g} / \mathrm{L})$ and tetracycline $(\geq 16 \mu \mathrm{g} / \mathrm{L})$. The highest $\mathrm{MIC}$ value reported in erythromycin was $0.5 \mu \mathrm{g} / \mathrm{L}$ and the lowest was $\leq 0.25 \mu \mathrm{g} /$, which were all considered sensitive.

The highest MIC value reported for vancomycin was $4 \mu \mathrm{g} / \mathrm{L}$ and the lowest was $\leq 0.5 \mu \mathrm{g} / \mathrm{L}$, which were all considered sensitive. Linezolid was reported sensitive with MICs ranging from $1 \mu \mathrm{g} / \mathrm{L}$ to $2 \mu \mathrm{g} / \mathrm{L}$. The smallest inhibitory zone reported for ceftriaxone was $25 \mathrm{~mm}$ and the biggest was $33 \mathrm{~mm}$ which were all considered as sensitive.

\section{Gene based resistance of GBS isolates}

All isolates were tested for the presence of tetracycline resistance genes i.e. tet $(\mathrm{M})$ and tet $(\mathrm{O})$ with multiplex PCR, using primers described in previous studies [13,
20]. In total, 16 isolates possessed tet $(\mathrm{M})$ whereas tet $(\mathrm{O})$ was found in none of the isolates, although they were all phenotypically resistant to tetracycline. Amplicons for tet $(\mathrm{M})$ have 347 base pairs and for tet $(\mathrm{O})$ have 548 base pairs [20].

\section{Polysaccharide capsular typing}

Following the amplification and electrophoresis, 9 isolates presented with amplicons of 521 base pairs and 1 isolate with an amplicon sized 770 base pairs. An amplicon of 521 base pairs is associated with capsular polysaccharide Ia whereas 770 base pairs is associated with capsular type Ib. Polysaccharide capsular type Ia was found in 9 (50\%) of isolates and Ib was found in $1(5.5 \%)$ of the total isolates. The remaining eight (44.4\%) isolates could not be classified using PCR. Polysaccharide capsular type IX was not assessed in this study.

\section{Discussion}

The prevalence of GBS among pregnant women found in this study $(5.7 \%)$ was lower compared to what was

Table 2 Association of obstetric factors and GBS colonisation among pregnant women

\begin{tabular}{|c|c|c|c|c|}
\hline Characteristic & Category & GBS non-colonised frequency $(n=198)$ & GBS colonised frequency $(n=12)$ & $P$ value \\
\hline \multirow[t]{3}{*}{ Parity } & 0 & $43(21.7 \%)$ & $2(16.7 \%)$ & 0.659 \\
\hline & $1-2$ & $82(41.4 \%)$ & $4(33.3 \%)$ & \\
\hline & $\geq 3$ & $73(36.9 \%)$ & $6(50.0 \%)$ & \\
\hline \multirow[t]{3}{*}{ Still births } & 0 & $183(92.4 \%)$ & $12(100 \%)$ & 0.613 \\
\hline & $1-2$ & $13(6.6 \%)$ & $0(0.0 \%)$ & \\
\hline & $\geq 3$ & $2(1.0 \%)$ & $0(0.0 \%)$ & \\
\hline \multirow[t]{3}{*}{ Miscarriages } & 0 & $178(89.9 \%)$ & $10(83.3 \%)$ & 0.471 \\
\hline & $1-2$ & $20(10.1 \%)$ & $2(16.7 \%)$ & \\
\hline & $\geq 3$ & $0(0.0 \%)$ & $0(0.0 \%)$ & \\
\hline
\end{tabular}


Table 3 Antimicrobial susceptibility patterns of GBS isolates to commonly used drugs

\begin{tabular}{|c|c|c|c|c|c|c|}
\hline \multirow{3}{*}{$\begin{array}{l}\text { Antimicrobial } \\
\text { agent }\end{array}$} & \multicolumn{6}{|c|}{ Percentage of GBS antibiotics sensitive, intermediate and resistant } \\
\hline & \multicolumn{2}{|l|}{ Sensitive (S) } & \multicolumn{2}{|c|}{ Intermediate (I) } & \multicolumn{2}{|c|}{ Resistant (R) } \\
\hline & Frequency & Percentage & Frequency & Percentage & Frequency & Percentage \\
\hline Penicillin & 18 & $100 \%$ & 0 & $0 \%$ & 0 & $0 \%$ \\
\hline Ampicillin & 18 & $100 \%$ & 0 & $0 \%$ & 0 & $0 \%$ \\
\hline Ceftriaxone & 18 & $100 \%$ & 0 & $0 \%$ & 0 & $0 \%$ \\
\hline Erythromycin & 18 & $100 \%$ & 0 & $0 \%$ & 0 & $0 \%$ \\
\hline Clindamycin & 18 & $100 \%$ & 0 & $0 \%$ & 0 & $0 \%$ \\
\hline Vancomycin & 18 & $100 \%$ & 0 & $0 \%$ & 0 & $0 \%$ \\
\hline Tetracycline & 0 & $0 \%$ & 0 & $0 \%$ & 18 & $100 \%$ \\
\hline Linezolid & 18 & $100 \%$ & 0 & $0 \%$ & 0 & $0 \%$ \\
\hline Chloramphenicol & 18 & $100 \%$ & 0 & $0 \%$ & 0 & $0 \%$ \\
\hline
\end{tabular}

reported in a similar study conducted in Windhoek, Namibia in 2016, whereby the prevalence of GBS colonisation was reported at $13.6 \%$ [6]. Different recruitment centres were included in the current study, which comprise of a different population characteristic from the study by Engelbrecht et al., 2016 [6]. The prevalence in this current study is lower than the $31.6 \%$ found in Zimbabwe in 2000 [7], 30.9\% in South Africa in 2012 [9, 17], 37\% in South Africa in 2019 [8] and $21.2 \%$ in Malawi in 2010 [10].

The findings of this current study are similar to those reported in a Mozambican study, whereby a colonisation rate of $1.8 \%$ was obtained [11]. However, in the Mozambican study swabs were inoculated in Todd-Hewitt broth with only gentamycin $(8 \mu \mathrm{g} / \mathrm{ml}$ of agar) and the broth was sub-cultured onto human blood agar. The use of gentamycin alone without nalidixic acid can cause overgrowth of enterobacteriaceae organisms over GBS, hence reducing the growth of GBS. Furthermore, human blood used in preparation of blood agar might have contained inhibitory substances against the growth of GBS [11].

In the current study, 10 (83.3\%) women colonised with GBS were rural based while 2 (16.7\%) were urban based. This difference was however not statistically significant ( $P$ value 0.708$)$. In a similar study conducted in Dr. George Mukhari hospital, South Africa, more of the colonised women were dwelling in the urban areas [9]. This finding was however also not statistically significant ( $P$ value 0.08 ). It was observed in this study that majority (9) of GBS colonised women were not married (75.0\%), compared to married women (3). There was however no significant statistical association between GBS colonisation and marital status ( $P$ value 0.921$)$. This agrees with the study conducted at Dr. George Mukhari hospital, South Africa, which reported that the majority of colonised women were single, divorced or widowed followed by cohabiting women ( $P$ value 0.56$)$ [9]. In another study conducted in Windhoek by Engelbrecht et al., 2016, more single women were colonised compared to married women $(P$ value 0.315$)[6]$. Both findings were not statistically significant.

Group B streptococcus colonisation did not appear to be linked to obstetric factors such as history of miscarriages and still births, as women with no history of still births (12) and miscarriages (10) were largely colonised (100 and $83.3 \%$ respectively). These findings did not have any statistical significance $(P$ value 0.613 and 0.471 respectively). However, GBS colonisation had shown to increase with parity, $50.0 \%$ in women with parity exceeding two, $33.3 \%$ in women with one or two previous deliveries and $16.7 \%$ in women without previous deliveries. This was however not statistically significant $(P$. value 0.659). In the Saudi Arabian study conducted at Makkah, a significant statistical association was found between parity and GBS colonisation [21].

Similarly, GBS colonisation did not appear to be linked to history of miscarriages and still births in the South African study, as the carriage rate was greater in women who had no history of miscarriages and still births compared to the opposite. These were equally not statistically significant findings $(P$ value 0.33 and 0.24 respectively) [9]. In contrast to the findings of this current study, a study by Monyama et al., 2016 [9], in South Africa reported that women with multiple deliveries exceeding two were less affected by GBS compared to women who had one to two deliveries and those with zero parity. However, there was no statistical significance ( $P$ value 0.24$)$ [9].

In the current study, GBS showed sensitivity to penicillin, ampicillin, ceftriaxone, vancomycin, chloramphenicol and linezolid by $100 \%$. This correlates with the findings of the study done in Windhoek, where 100\% susceptibility was reported to penicillin, ampicillin, ceftriaxone, vancomycin and linezolid. All isolates were found to be sensitive to clindamycin and erythromycin by $100 \%$. This does not correlate with findings of the 
Windhoek study, whereby $88.9 \%$ sensitivity and $11.1 \%$ resistance was reported for erythromycin, while for clindamycin $72.6 \%$ sensitivity, $18.8 \%$ intermediate sensitivity and $8.5 \%$ resistance was reported [6].

Since only 18 GBS isolates were obtained from the current study, $100 \%$ susceptibility to clindamycin and erythromycin might not be a true reflection of the antimicrobial susceptibility patterns of GBS in the two regions, as a bigger number of isolates might have reflected a different picture. Furthermore, this current study revealed a $100 \%$ resistance to tetracycline, while the previous study has revealed $94.9 \%$ resistance to tetracycline and $5.1 \%$ susceptibility thereof. This difference may be attributable to the differences in the locations of the two studies and also different sample sizes. High levels of resistance to tetracycline by GBS is an indication of growing resistance to commonly used antibiotics especially those used in both humans and animals [6-11].

The findings of our study are in correlation with another study conducted in Ayder referral hospital and Mekelle health centre, Mekelle, Northern Ethiopia, whereby GBS was reportedly $100 \%$ susceptible to penicillin, ampicillin, erythromycin, and vancomycin [1]. However, in the same study, intermediate GBS susceptibility was reported to chloramphenicol by $42.1 \%$ and ceftriaxone by $26.3 \%$, which opposes the findings of our study [1].

On the contrary, our study findings are different from the findings of a similar study conducted in Ghandi memorial and Tikur Anbessa, Addis Ababa, Ethiopia, where GBS was found to be $55 \%$ susceptible to penicillin, $91 \%$ sensitive to ampicillin and all isolates except one were susceptible to erythromycin [22]. Increased resistance to penicillin in this area was attributable to a wide nonprescription use of penicillin due to weak drug control mechanisms [22].

Another study conducted in Gabon, Central Africa to determine capsular type distribution and antimicrobial susceptibility of GBS in pregnant women found that all GBS isolates were susceptible to clindamycin, linezolid, vancomycin and benzyl penicillin which correlates with the findings of our study [16]. Fourteen isolates were however found intermediary susceptible to erythromycin, which contrasts the findings of our study. However, no inducible clindamycin resistance was found in the Gabon study, which draws a parallel between the two studies [16].

In the neighbouring South Africa, a study conducted to assess the antimicrobial resistance of $S$. agalactiae isolated from pregnant women in Garankuwa found that all strains were $100 \%$ susceptible to penicillin, ampicillin and vancomycin, which is similarly demonstrated in our study [8]. The same study however found some strains to be resistant to erythromycin, clindamycin, tetracycline and chloramphenicol by 21.1, 17.2, 94.5 and $24.9 \%$ respectively, which distinguishes the two study findings [8]. In a comparable study conducted in Soweto, South Africa to determine the risk of GBS sepsis in infants exposed to HIV, all isolates were penicillin sensitive, and macrolide resistance was observed in 5.5\% [23].

Generally, GBS has shown uniform sensitivity to penicillin, ampicillin, vancomycin, ceftriaxone and linezolid across many settings. Resistance to tetracycline was reported at $100 \%$ in our study compared to many previous studies, even though they also reported quite high percentages of resistance to tetracycline. Resistance to erythromycin and clindamycin was however not reported in our study, as opposed to other studies. These differences may be attributed to variations in capsular types common in different locations. In additions, fewer GBS isolates were obtained in the current study as compared to other studies, hence the differences in percentages of antimicrobial susceptibility.

None of the isolates phenotypically resistant to tetracycline presented with tet $(\mathrm{O})$ gene, which confers resistance against tetracycline in addition to tet $(\mathrm{M})$ gene [13]. A related study which was conducted in Windhoek has found tet $(\mathrm{M})$ in 114/117 GBS isolates and of these, 111 were tetracycline resistant as interpreted by the Vitek 2 [6]. Based on that study, six of the isolates that possessed tet $(\mathrm{M})$ did not appear to be phenotypically resistant to tetracycline [6]. This does not concur with our findings, as all isolates presenting with tet $(\mathrm{M})$ were phenotypically resistant to tetracycline in our study. Only tetracycline resistance genes were inspected in our study, as all isolates from this study have only shown phenotypical resistance to tetracycline.

Our study found capsular type Ia to be common among the pregnant women screened. A similar study conducted to determine the antigenic distribution of $S$. agalactiae isolates from pregnant women at Garankuwa hospital in South Africa revealed that capsular type III was the most common capsular type (29.7\%), followed by Ia (25.6\%), II (15.6\%) IV (8.6\%), V (10.9\%) and Ib (8.6\%) [17]. These imply that the prominent capsular types associated with this population were III, Ia and II. Differences in geographical locations of the two studies may attribute to the differences in capsular types found in the two studies. Non-typable strains reported in this study could have been a result of capsular type IX which was not assessed. A combination of both serology and molecular analysis may also have improved classification of the non-typables.

Another South African study conducted on pregnant mothers attending prenatal clinics in Soweto concluded that capsular type III was more associated with persistent colonisation throughout the study (29\%) than Ia (18\%) and V (6\%) [18]. In a Zimbabwean study, the 
following capsular types were identified as follows: la, lb., II, III and V at 15.7, 11.6, 8.3, 38.8 and $24.0 \%$ respectively [19], which corresponds with our findings.

GBS colonises pregnant women presenting the risk of vertical transmission to the baby during the process of giving birth. Although the prevalence of GBS was low in this current study, it provides further information that some women are colonised with GBS at the late stages of pregnancy and are at risk of passing it on to the babies. Antimicrobial resistance was low to commonly used antibiotics except tetracycline in this study. However, there is need for continuous monitoring of antibiotic resistance as studies in other geographic locations have reported varying degrees of resistance by GBS to antibiotics. Although GBS is not routinely screened in pregnant women in Namibia, the results of this study are important for informing future policy considerations on its screening and management among pregnant women in the country and for empirical treatment of those colonised with GBS.

\section{Conclusions}

In the current study, the prevalence of GBS colonisation in women who attended antenatal screening at Okongo, Eenhana and Onandjokwe state hospitals was 5.7\%. Twelve women were colonised in total and of these, $25.0 \%$ carried GBS in their lower vagina and rectum, $58.0 \%$ in the lower vagina only and $17.0 \%$ in the rectum only. Our study findings have revealed that there was no significant statistical association between GBS colonisation and age, habitat, marital status, educational level and employment status. Similarly, there was also no statistically significant association between GBS colonisation and parity, history of still births and miscarriages.

Antimicrobial susceptibility was reported at $100 \%$ sensitive for ampicillin, penicillin, ceftriaxone, clindamycin, erythromycin, vancomycin, linezolid and chloramphenicol. Resistance to tetracycline was reported at $100 \%$. However, $100 \%$ susceptibility to erythromycin and clindamycin may be due to a smaller number of GBS isolates obtained from this study. The tetracycline resistance gene tet $(\mathrm{M})$ was present in $88.9 \%$ of isolates and $11.1 \%$ had none, regardless of being phenotypically resistant to tetracycline. None of the isolates possessed detectable $\operatorname{tet}(\mathrm{O})$ resistance gene.

Polysaccharide capsular type Ia was found in 9 (50\%) of isolates and Ib was found in 1 (5.5\%) of the total isolates. The remaining 8 (44.4\%) isolates could not be classified using PCR.

\section{Methods}

\section{Study design}

This was a descriptive cross-sectional study which gathered descriptive data such as socio-economic, demographic characteristics and obstetric factors directly from participants using a questionnaire.

\section{Study population}

The population comprised of pregnant women between 35 and 37 weeks gestation, who attended antenatal clinics at Onandjokwe, Eenhana and Okongo state hospitals between May and September 2018. Women who had taken antibiotics 2 weeks prior to the study, as well as those aged below 16 years were excluded from the study.

\section{Sample size}

The sample size was calculated based on the prevalence rate of GBS colonisation in pregnant women found in Windhoek, which was $13.6 \%$ [6], using the following formula adopted from a prior study [1]. The expected sample size was 181 participants ( $n=181$ participants).

A total of 210 subjects were screened, 98 from Onandjokwe hospital, 93 from Eenhana hospital and 19 from Okongo hospital.

\section{Specimen collection}

A convenience sampling technique was used in this study and samples were collected consecutively. A lower vaginal and a rectal swab were collected from each participant by qualified clinicians using sterile cotton-tipped swabs. A lower vaginal swab was collected by inserting and brushing a sterile swab $2 \mathrm{~cm}$ into the vagina, periurethral area and labia. A rectal swab was collected by inserting a sterile swab $1 \mathrm{~cm}$ into the anus, rubbing the wall of the anal canal as described before [12]. The swabs were inserted into Amie's transport medium for preservation of bacteria. Each specimen was labelled with a unique identification. Specimens were transported at $2-8{ }^{\circ} \mathrm{C}$ to the laboratory within an hour from collection. A cold chain protocol was observed during specimen transport and samples were cultured within an hour after reaching the laboratory.

\section{Specimen culturing}

Each swab was inoculated directly onto 5\% Sheep blood agar with colistin and nalidixic acid (BCNA), followed by inoculation into Todd-Hewitt broth (TH) supplemented with colistin and nalidixic acid. The culture plates and broths were incubated at $37^{\circ} \mathrm{C}$ in $\mathrm{CO}_{2}$ for $18-24 \mathrm{~h}$. After incubation, BCNA culture plates were examined for presence of large, whitish-grey and translucent colonies with a narrow zone of $\beta$-haemolysis while the ToddHewitt broths were subcultured onto BCNA agar. Subcultured $\mathrm{BCNA}$ plates were incubated at $37^{\circ} \mathrm{C}$ in $\mathrm{CO}_{2}$ for $18-24 \mathrm{~h}$ and examined for presumptive GBS colonies. The Columbia CNA agar, Todd Hewitt broth, colistin and nalidixic acid antibiotics were obtained from 
Rochelle Chemicals and Laboratory Equipment, Johannesburg, South Africa.

\section{Isolation and identification of GBS}

Single colonies that presented with a narrow or large zone of $\beta$-haemolysis on the BCNA or TH-BCNA were subjected to the CAMP test for presumptive identification. S. agalactiae ATCC 12403 was used as a positive control and Streptococcus pyogenes ATCC 1244 as negative control. A known $\beta$-haemolytic toxin producing Staphylococcus aureus clinical isolate was used in this test. Presumptive GBS isolates were tested again using Vitek 2 before they were confirmed as GBS using molecular techniques by amplifying the $s c p B$ gene [24].

\section{DNA extraction}

DNA of positive and negative controls (ATCC 12403 and ATCC 1244 respectively) and test isolates was extracted using the boiling method as described in a prior study [4]. Pure cultures of presumptive isolates were harvested from nutrient agar plates and emulsified in $200 \mu \mathrm{L}$ of DNA free water in respective Eppendorf tubes using sterile plastic loops, followed heating at $100^{\circ} \mathrm{C}$ on the heating block for $15 \mathrm{~min}$. Eppendorf tubes were centrifuged at $8000 \mathrm{rpm}(\mathrm{rpm})$ for $10 \mathrm{~min}$. The supernatant containing DNA was transferred to a clean labelled tube, and stored at $-20^{\circ} \mathrm{C}$ before use.

\section{PCR for identification}

A primer pair from Inqaba Biotechnical Industries (Pty) Ltd. (Pretoria, South Africa) 5'-ACAACGGAAGGCGCTACTGTTC-3' (forward primer) and 5'-ACCTGGTGTTTGACCTGAACTA-3' (reverse primer) which targeted the $s c p B$ gene was used for confirmation of GBS [20]. PCR reaction mixture was

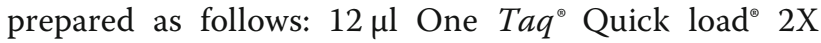
master mix with standard buffer, $10.5 \mu \mathrm{l}$ nuclease free water, $1 \mu \mathrm{l}$ of forward and reverse primer, and $5 \mu \mathrm{l}$ DNA template, giving a final volume of $29.5 \mu \mathrm{l}$. The PCR conditions were as follows: 1 cycle at $94{ }^{\circ} \mathrm{C}$ for 4 min (initial denaturation), 35 cycles at $93^{\circ} \mathrm{C}$ for $1 \mathrm{~min}$ (denaturation), $57.6{ }^{\circ} \mathrm{C}$ for $1 \mathrm{~min}$ (annealing), $72{ }^{\circ} \mathrm{C}$ for $1 \mathrm{~min}$ (elongation), 1 cycle at $72^{\circ} \mathrm{C}$ for 7 min (further elongation) and $4{ }^{\circ} \mathrm{C}$ dwelling temperature using a BioRad thermal cycler (Johannesburg, South Africa).
The amplicons were electrophoresed on a $2 \%$ agarose gel electrophoresis with $1 x$ Tris-Acetate EDTA (TAE) buffer, at $110 \mathrm{~V}$ for $45 \mathrm{~min}$. A 1000 base pair (bp) DNA ladder, positive and negative control were included. The gel was visualised under the SYN GENE BIO IMAGING ultra violet system (Cambridge, United Kingdom). The sizes of amplicons were determined using the DNA molecular weight size standard.

\section{Antimicrobial sensitivity testing}

Antimicrobial sensitivity testing for sixteen confirmed isolates was performed using the Vitek 2 system (bioMerieux, Midrand, South Africa). This method employed gram positive antimicrobial sensitivity cards (AST-ST01). This card tested for penicillin, ampicillin, erythromycin, clindamycin, vancomycin, tetracycline, linezolid \& chloramphenicol. Ceftriaxone was tested using the Kirby-Bauer disk diffusion method. Two isolates were tested using the Kirby-Bauer disc diffusion method against all antibiotics. Minimum inhibitory concentration (MIC) breakpoint results and disc zones were interpreted as stipulated by the Clinical Laboratory Standards Institute [25].

\section{Multiplex PCR for gene-based resistance testing}

Specific oligonucleotide primers (Table 4) from Inqaba Biotechnical Industries (Pty) Ltd. (Pretoria, South Africa) were used to screen for genotypic resistance $[13,26]$. The reaction mixture was prepared as follows: $12 \mu$ l One $\mathrm{Taq}^{\circ}$ Quick load $^{\circ}$ 2X master mix with standard buffer, $10.5 \mu \mathrm{l}$ nuclease free water, $1 \mu \mathrm{l}$ of all forward and reverse primers, and $5 \mu \mathrm{l}$ DNA template, giving a final volume of $31.5 \mu \mathrm{l}$. The multiplex PCR conditions were as follows: 1 cycle at $94{ }^{\circ} \mathrm{C}$ for $4 \mathrm{~min}$ (initial denaturation), 35 cycles at $93^{\circ} \mathrm{C}$ for $1 \mathrm{~min}$ (denaturation), $57.6^{\circ} \mathrm{C}$ for 1 min (annealing), $72{ }^{\circ} \mathrm{C}$ for 1 min (elongation), 1 cycle at $72{ }^{\circ} \mathrm{C}$ for $7 \mathrm{~min}$ (further elongation) and $4{ }^{\circ} \mathrm{C}$ dwelling temperature using a BioRad thermal cycler (Johannesburg, South Africa). The amplicons were electrophoresed on a $2 \%$ agarose gel electrophoresis with $1 x$ TrisAcetate EDTA (TAE) buffer, at $110 \mathrm{~V}$ for $45 \mathrm{~min}$. A 1000 base pair (bp) DNA ladder, positive and negative control were included. The gel was visualised under the SYN GENE BIO IMAGING ultra violet system (Cambridge, United Kingdom). The sizes of amplicons were

Table 4 Oligonucleotide primers used in multiplex PCR for gene based resistance testing

\begin{tabular}{llll}
\hline Primer & Target & Primer sequence $\mathbf{5}^{\prime} \mathbf{-} \mathbf{3}^{\prime}$ & Size \\
\hline tetmS $-\mathrm{F}$ & tet $(\mathrm{M})$ & GTCTTGCATATATACGCCTTTATAGTGGAGTACTACATTTACGAG & 374 bp \\
tetmA $-\mathrm{R}$ & tet $(\mathrm{M})$ & CCACGTAATATCGTAGAAGCGGATCACTATCTGAG & 548 bp \\
tetoS $-\mathrm{F}$ & tet $(\mathrm{O})$ & CGTATATATAGCGGAACATTGCATTTGAGGG & \\
teto $\mathrm{A}-\mathrm{R}$ & tet $(\mathrm{O})$ & CGGCTCTATGGACAACCCGACAGAAG & \\
\hline
\end{tabular}


Table 5 Oligonucleotide Primers for polysaccharide capsular typing

\begin{tabular}{|c|c|c|c|}
\hline Primer & Target & Primer sequence & Size bp \\
\hline$\overline{l a-F}$ & cpslaH & 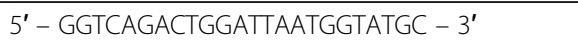 & $521 \& 1826 \mathrm{bp}$ \\
\hline la-R & cpsiAh & 5' - GTAGAAATAGCCTATATACGTTGAATGC - 3' & \\
\hline $\mathrm{Ib}-\mathrm{F}$ & cpsibJ & $5^{\prime}$ - TAAACGAGAATGGAATATCACAAACC - 3' & $770 \mathrm{bp}$ \\
\hline $\mid b-R$ & $c p s / b K$ & $5^{\prime}$ - GAATTAACTTCAATCCCTAAACAATATCG - 3' & \\
\hline$\|-F$ & $\operatorname{cps} 2 K$ & 5' - GCTTCAGTAAGTATTGTAAGACGATAG - 3' & $397 \mathrm{bp}$ \\
\hline$\|-\mathrm{R}$ & $\operatorname{cps} 2 K$ & $5^{\prime}$ - TTCTCTAGGAAATCAAATAATTCTATAGGG - 3' & \\
\hline III-F & $\operatorname{cps} 1 a / 2 / 31$ & $5^{\prime}$ - TCCGTACTACAACAGACTCATCC - 3' & $1826 \mathrm{bp}$ \\
\hline III-R & $\operatorname{cps} 1 a / 2 / 3 \mathrm{~J}$ & $5^{\prime}$ - AGTAACCGTCCATACATTCTATAAGC - 3' & \\
\hline IV-F & $\operatorname{cps} 4 \mathrm{~N}$ & $5^{\prime}$ - GGTGGTAATCCTAAGAGTGAACTGT - 3' & $578 \mathrm{bp}$ \\
\hline IV-R & $\operatorname{cps} 4 \mathrm{~N}$ & $5^{\prime}$ - CCTCCCCAATTTCGTCCATAATGGT - 3' & \\
\hline V-F & $\operatorname{cps} 50$ & $5^{\prime}$ - GAGGCCAATCAGTTGCACGTAA - 3' & $701 \mathrm{bp}$ \\
\hline V-R & $\operatorname{cps} 50$ & 5' - AACCTTCTCCTTCACACTAATCCT - 3' & \\
\hline VI-F & cps6l & $5^{\prime}$ - GGACTTGAGATGGCAGAAGGTGAA - 3' & $487 \mathrm{bp}$ \\
\hline VI-R & cps6l & $5^{\prime}$ - CTGTCGGACTATCCTGATGAATCTC - 3' & \\
\hline VII-F & cps $7 M$ & $5^{\prime}$ - CCTGGAGAGAACAATGTCCAGAT - 3' & $371 \mathrm{bp}$ \\
\hline VII-R & $\operatorname{cps} 7 \mathrm{M}$ & 5' - GCTGGTCGTGATTTCTACACA - 3' & \\
\hline VIIII-F & $\operatorname{cps} 8 \mathrm{~J}$ & $5^{\prime}-$ AGGTCAACCACTATATAGCGA - 3' & $282 \mathrm{bp}$ \\
\hline VIII-R & $\operatorname{cps} 8 \mathrm{~J}$ & $5^{\prime}$ - TCTTCAAATTCCGCTGACTT - 3' & \\
\hline
\end{tabular}

determined using the DNA molecular weight size standard.

\section{PCR for polysaccharide capsular typing}

Oligonucleotide primer pairs (Table 5) from Inqaba Biotechnical Industries (Pty) Ltd. (Pretoria, South Africa) were used in capsular polysaccharide typing, in three different categories, i.e. type Ia - III, IV - VII and VIII [21]. The PCR reaction mixture was prepared as follows: $12 \mu$ l One $\operatorname{Taq}^{\oplus}$ Quick load $^{\oplus} 2 \mathrm{X}$ master mix with standard buffer, $10.5 \mu \mathrm{l}$ nuclease free water, $1 \mu \mathrm{l}$ of all forward and reverse primers, and $5 \mu \mathrm{l}$ DNA template, giving a final volume of $35.5 \mu \mathrm{l}$ for type Ia - III \& IV - VII, and a final volume of $29.5 \mu \mathrm{l}$ for type VIII categories.

The thermocycling conditions were as follows: 1 cycle at $94{ }^{\circ} \mathrm{C}$ for $4 \mathrm{~min}$ (initial denaturation), 35 cycles at $93^{\circ} \mathrm{C}$ for $1 \mathrm{~min}$ (denaturation), $58^{\circ} \mathrm{C}$ for $1 \mathrm{~min}$ (annealing) (for type Ia - III), $59{ }^{\circ} \mathrm{C}$ (for type IV - VII) \& $56^{\circ} \mathrm{C}$ (for type VIII), $72{ }^{\circ} \mathrm{C}$ for $1 \mathrm{~min}$ (elongation), 1 cycle at $72{ }^{\circ} \mathrm{C}$ for $7 \mathrm{~min}$ (further elongation) and $4{ }^{\circ} \mathrm{C}$ dwelling temperature using a BioRad thermal cycler (Johannesburg, South Africa). The amplicons were electrophoresed on a $2 \%$ agarose gel electrophoresis with 1xTrisAcetate EDTA (TAE) buffer, at $110 \mathrm{~V}$ for $45 \mathrm{~min}$. A 1000 base pair (bp) DNA ladder, positive and negative control were included. The gel was visualised under the SYN GENE BIO IMAGING ultra violet system (Cambridge, United Kingdom). The sizes of amplicons were determined using the DNA molecular weight size standard.

\section{Data analyses}

Data was analysed using the Statistical Package for Social Sciences version 22. The Pearson's Chi square was used to test for relationships between categorical variables. Descriptive statistics were used to summarise the frequencies and they were presented as cross tabulations. A $P$ value less than 0.05 represented statistical significance.

\section{Abbreviations \\ A: Adenine; ATCC: American Type Culture Collection; BBB: Blood Brain Barrier; BCNA: Columbia Sheep Blood with Colistin and Nalidixic acid; BibA: GBS immunogenic bacterial adhesion; C: Cytosine; CAMP : Christie, Atkins, Munch and Petersen test; CDC: Centres for Diseases Control and Prevention; CLSI: Clinical Laboratory Standards Institute; DNA: Deoxy Ribonucleic Acid; EOD: Early Onset Disease; G: Guanine; GBS: Group B Streptococcus; HIV: Human Immuno-Deficiency Virus; IAP: Intrapartum Antibiotic Prophylaxis; Lmb: Laminin binding protein; LOD: Late Onset Disease; LVS: Lower Vaginal Swab; MIC: Minimum Inhibitory Concentration; NIP: Namibia Institute of Pathology; NUST: Namibia University of Science and Technology; PCR: Polymerase Chain Reaction; rRNA: Ribosomal Ribonucleic Acid; S. agalactiae: Streptococcus agalactiae; S. aureus: Staphylococcus aureus; SBA: Sheep Blood Agar; scpB: Group B streptococcal C5a peptidase; SfbA: Streptococcal fibronectin binding protein; SPSS: Statistical Package for Social Sciences; S. pyogenes: Streptococcus pyogenes; T: Thymine; TAE: Tris- Acetate EDTA buffer; Taq: Polymerase enzyme produced by Thermophilus aquaticus; TH: Todd Hewitt}

\section{Acknowledgements}

We would like to thank NIP and NUST for financial support. The Department of Health Sciences, Medical Laboratory Sciences Programme for general support during the conduct of the study. Our sincere thanks go to all the women who participated in the study and the nurses from the study hospitals who helped in the collection of samples for the study.

\section{Authors' contributions}

All authors the authors significantly contributed to the conduct of the study. ELH, MM and SRM conceptualised the research and designed the work. SRM 
supervised the study and ELH collected data and cultured specimens. ELH and $\mathrm{MM}$ carried the molecular screening of isolates and all authors contributed to the drafting of the manuscript and revision and approved it.

\section{Funding}

Funding for this study was provided by the Namibia Institute of Pathology (NIP) and Namibia University of Science and Technology (NUST).

\section{Availability of data and materials}

The datasets used and/or analysed during the current study are available from the corresponding author on reasonable request.

\section{Declarations}

\section{Ethics approval and consent to participate}

Permission to conduct the research was obtained from NUST while ethical clearance was granted by the Ministry of Health and Social Services (MoHSS), Namibia research committee, reference 17/3/3 EH. Written informed consent was obtained from each participant.

\section{Consent for publication}

Not applicable.

\section{Competing interests}

The authors declare that they have no competing interests.

Received: 12 August 2020 Accepted: 21 July 2021

Published online: 05 August 2021

\section{References}

1. Alemseged G, Niguse S, Hailekiros H, Abdulkadir M, Saravanan M, Asmelash T. Isolation and anti-microbial susceptibility pattern of group B streptococcus among pregnant women attending antenatal clinics in Ayder referral hospital and Mekelle health Centre, Mekelle, Northern Ethiopia. BioMed Central. 2015:8:1-8.

2. Doran KS, Nizet V. Molecular pathogenesis of neonatal group B streptococcal infection: no longer in its infancy. Mol Microbiol. 2004;54(1): 23-31.

3. Heelan JS, Hasenbein ME, McAdam AJ. Resistance of group B streptococcus to selected antibiotics, including erythromycin and clindamycin. J Clin Microbiol. 2004:42(3):1263-4

4. Gygax SE, Schuyler JA, Kimmel LE, Trama JP, Mordechai E, Adelson ME. Erythromycin and clindamycin resistance in group B streptococcal clinical isolates. Am Soc Microbiol. 2006;50(5):1875-7.

5. Joachim A, Matee MI, Massawe FA, Lyamuya EF. Maternal and neonatal colonisation of group B streptococcus at Muhimbili National Hospital in Dar Es Salaam, Tanzania: prevalence, risk factors and antimicrobial resistance. BioMed Central Public Health. 2009;9:1-7.

6. Engelbrecht F, Moyo SR, Maposa I, Mukesi M, Khan S. The antimicrobial susceptibility and gene-based resistance of Streptococcus agalactiae (Group B streptococcus) in pregnant women in Windhoek (Khomas region), Namibia. Medical Technology SA. 2016;30(2):9-14.

7. Moyo SR, Mudzori J, Tswana SA, Maeland J. Prevalence, capsular type distribution, anthropometric and obstetric factors of group B streptococcus (Streptococcus agalactiae) colonisation in pregnancy. Central Afr J Med. 2000;46(5):115-20.

8. Bolukaoto JY, Monyama CM, Chukwu MO, Lekala SM, Nchabeleng M, Maloba MR ... Moyo SR. Antibiotic resistance of Streptococcus agalactiae isolated from pregnant women in Garankuwa, South Africa. BioMed Central Research Notes. 2015:8:1-7.

9. Monyama MC, Bolukaoto JY, Chukwu MO, Maloba MRB, Moyo SR, Mavenyengwa RT, et al. Group B Streptococcus colonisation in pregnant women at Dr. George Mukhari hospital, South Africa. South Afr J Infect Dis. 2016;1(1):1-5.

10. Gray KJ, Kafulafula G, Matemba M, Kamdolozi M, Membe G, French N. Group B streptococcus and HIV infection in pregnant women, Malawi, 2008-2010. Emerg Infect Dis. 2011;17(10):1932-5.

11. de Steenwinkel FDO, Tak HV, Muller AE, Nouwen JL, Oostvogel PM, Mocumbi SM. Low carriage rate of group B streptococcus in pregnant women in Maputo. Mozambique Trop Med Int Health. 2008;13(3):427-9.
12. Centre for Diseases Control and Prevention. Algorithm for screening Group B Streptococcus colonisation.2010. https://www.cdc.gov/Groupbstrep/ guidelines/algorithms-tables.html. Accessed 14 June 2017.

13. Zeng X, Kong F, Wang H, Darbar A, Gilbert GL. Simultaneous detection of nine antibiotic resistance-related genes in Streptococcus agalactiae using multiplex PCR and reverse line blot hybridization assay. Am Soc Microbiol. 2006;50(1):204-9.

14. Zhao Z, Kong F, Zeng X, Gidding HF, Morgan J, Gilbert GL. Distribution of genotypes and antibiotic resistance genes among invasive Streptococcus agalactiae (group B streptococcus) isolates from Australasian patients belonging to different age groups. Eur Soc Clin Microbiol Infect Dis. 2008; 14:260-7.

15. Teatero S, McGeer A, Low DE, Li A, Demczuk W, Martin I, et al. Characterisation of invasive group B streptococcus strains from the greater Toronto area, Canada. J Clin Microbiol. 2014;52(5):1441-7.

16. Belard S, Toepfner N, Capan-Melser M, Mombo-Ngoma G, Zoleko-Manego R, Groger M ... Berner R. Streptococcus agalactiae capsular type distribution and antimicrobial susceptibility in pregnant women in Gabon, Central Africa. Sci Rep. 2015;5:1-4.

17. Chukwu MO, Mavenyengwa RT, Monyama CM, Bolukaoto JY, Lebelo SL, Maloba MRB, et al. Antigenic distribution of Streptococcus agalactiae isolates from pregnant women at Garankuwa hospital - South Africa. Germs. 2015; 5(4):125-33.

18. Kwatra G, Adrian PV, Shiri T, Buchmann EJ, Cutland CL, Madhi SA. Capsular type-specific acquisition and loss of group B streptococcus recto-vaginal colonisation in late pregnancy. PLoS One. 2014;9(6):1-9.

19. Mavenyengwa RT, Maeland JA, Moyo SR. Serotype markers in a Streptococcus agalactiae collection from Zimbabwe. Indian J Med Microbiol. 2010;28(4):313-9.

20. Poyart C, Jardy L, Quesne G, Berche P, Trieu-Cout P. Genetic basis of antibiotic resistance in Streptococcus agalactiae strains isolated in a French hospital. Antimicrob Agents Chemother. 2003;47(2):794-7.

21. Khan MA, Faiz A, Ashshia AM. Maternal colonisation of group $B$ Streptococcus: prevalence, associated factors and antimicrobial resistance. Ann Saudi Med. 2015;35(6):423-7.

22. Woldu ZL, Teklehaimanot TG, Waji ST, Gebremariam MY. The prevalence of Group B Streptococus recto-vaginal colonization and antimicrobial susceptibility pattern in pregnant mothers at two hospitals of Addis Ababa, Ethiopia. Reprod Health. 2014;11:80

23. Cutland CL, Schrag SJ, Thigpen MC, Velaphi SC, Wadula J, Adrian PV, et al. Increased risk for Group B streptococcus sepsis in young infants exposed to HIV, Soweto, South Africa, 2004-2008. Emerg Infect Dis. 2015;21(4):638-45.

24. Dmitrieve A, Suvorov A, Shen AD, Yang YH. Clinical diagnosis of group B streptococci by scpB gene based PCR. Indian J Med Res. 2004;119:233-6.

25. Clinical and Laboratory Standards Institute, editor. Performance standards for antimicrobial susceptibility testing. $28^{\text {th }}$ ed. Wayne: Clinical and Laboratory Standards Institute; 2018.

26. Poyart C, Tazi A, Reglier-poupet H, Billoet A, Tavares N, Raymond J, et al. Multiplex PCR assay for rapid and accurate capsular typing of group $B$ streptococci. J Clin Microbiol. 2007;45(6):1985-8.

\section{Publisher's Note}

Springer Nature remains neutral with regard to jurisdictional claims in published maps and institutional affiliations.

Ready to submit your research? Choose BMC and benefit from:

- fast, convenient online submission

- thorough peer review by experienced researchers in your field

- rapid publication on acceptance

- support for research data, including large and complex data types

- gold Open Access which fosters wider collaboration and increased citations

- maximum visibility for your research: over $100 \mathrm{M}$ website views per year

At BMC, research is always in progress.

Learn more biomedcentral.com/submissions 